\title{
Characterization of the Austenite Reformation Mechanisms as a Function of the Initial Ferritic State in a UNS S32304 Duplex Stainless Steel
}

\author{
Charles Henrique Xavier Morais Magalhães ${ }^{a}$, Geraldo Lúcio de Faria $^{a}$, Leonardo Evangelista
}

\author{
Lagoeiro $^{b}$, Jéssica Dornelas Silva ${ }^{a}$
}

${ }^{a}$ Escola de Minas-DEMET-LTM, Universidade Federal de Ouro Preto, Ouro Preto, MG, Brazil. ${ }^{b}$ Departamento de Geologia, Centro Politécnico, Universidade Federal do Paraná, Curitiba, PR, Brazil.

Received: December 25, 2016; Revised: June 20, 2017; Accepted: July 21, 2017

\begin{abstract}
Aiming to better understand the effects of heat treatment parameters on Ferrite-Austenite phase transformation in a 2304 duplex stainless steel different thermal cycles were applied to this steel in a quenching dilatometer. The obtained microstructures were characterized by optical microscopy, transmission electron microscopy and electron backscatter diffraction. It was noticed that the austenite formation mechanism is strongly dependent on initial ferritized state. If the initial structure is completely ferritized, the nitrogen supersaturated solid solution leads to chromium nitrides precipitation and the rate of austenite nucleation decreases. For higher cooling rates, the ferrite grain boundaries control the austenite nucleation rate. The higher the ferrite grain size, the lower the final austenite fraction. If the steel is cooled from a partial ferritized state, the ferrite-austenite phase boundaries work as austenite nucleation site and the austenite growth rate is favored due to the high interfacial energy and the austenitic structures becomes coarser.
\end{abstract}

Keywords: Duplex Stainless Steel, UNS S32304, Ferrite-Austenite, Phase Transformation, Heat Treatments.

\section{Introduction}

Duplex stainless steels (DSS) have been strongly used in many different applications. Some examples can be mentioned: shipbuilding, chemical, oil \& gas, and cellulose industries. This family of steels have been used due to their excellent combination of mechanical properties and corrosion resistance ${ }^{1-3}$. It is well known that DSS's property combination strongly depends on their balanced biphasic microstructure, constituted mainly of similar amounts of austenite $(\gamma)$ and ferrite $(\alpha)$, with small or no amounts of secondary phases as chromium nitrides and sigma ${ }^{1-4}$. The phase balance in the steel is obtained in the manufacture process by controlling the steel chemical composition and applying well planned thermomechanical treatments ${ }^{5,6}$. In the manufacturing process of duplex UNS S32304 the desired phase balance ( $50 \%$ of each primary phase) is obtained in temperatures around $1050^{\circ} \mathrm{C}$.

Many microstructural changes may occur in duplex stainless steels during heat processing (sheets heat treatments, sheets hot forming, welding, and others). In these processes, the desired phase balance may be lost ${ }^{7}$. For specific applications, the engineering project requires that the alloy be heat processed. The oil \& gas industry is an example.
For instance, in the oil \& gas industry, pipes and tubes must be joined by welding processes. The welding is a heating process that strongly change the steel microstructure. Both the melting zone (MZ) and heat affected zone (HAZ) have the morphology and phase amounts changed according to the welding thermal cycle variables ${ }^{4,8-11}$.

During the welding heat cycle, the alloy HAZ is heated up to temperatures around $1350^{\circ} \mathrm{C}$ in a relatively short time and hold at this temperature for few seconds. Afterwards the temperature was let drop down to the room temperature. During the heating and isothermal stages, most of austenite particles are dissolved into the ferritic phase, which undergoes a notable grain coarsening ${ }^{4}$.

In the cooling step, a fraction of ferrite changes to austenite. Depending on the transformation temperature, the austenite may occur with three different morphologies. Above the equilibrium Solvus temperature, at higher temperatures, the conditions are favorable for the allotriomorphic austenite (or grain boundary austenite). At intermediate temperatures, the Widmanstätten morphology prevails. At the lower temperatures of the equilibrium Solvus, the austenite forms as intragranular precipitates inside ferrite grains ${ }^{2,3,5}$. It is important to highlight that the austenite precipitation is a 
diffusional process (nucleation and growth stages). The austenite formation is controlled by a para-equilibrium mechanism, where the diffusion of interstitial elements, such as carbon and nitrogen, plays a fundamental role in the control of grain nucleation and growth ${ }^{8}$.

At $\mathrm{HAZ}$, nitrides as $\mathrm{Cr}_{2} \mathrm{~N}$ and $\mathrm{CrN}$ may be formed. The $\mathrm{Cr}_{2} \mathrm{~N}$ is normally formed due to a fast cooling from a ferritic solid solution. During the cooling, the supersaturation of nitrogen occurs in the ferrite and the $\mathrm{Cr}_{2} \mathrm{~N}$ precipitates because its precipitation kinetics is faster than the austenite one ${ }^{12}$. In this condition, the austenite formation is suppressed by nitrides precipitation. The low austenite volumetric fraction coupled to the nitrides presence is prejudicial to the alloy mechanical properties ${ }^{13}$.

Therefore, if a DSS is submitted to a thermal cycle, it is necessary to have control over the microstructural changes that may occur, aiming to obtain a material with desirable properties for a high performance application. The control of the possible microstructural changes is obtained by the correct manipulation of some important variables associated to the heating process, such as temperature, time, heating and cooling rates and others. So, it is very important to understand how the heat process and the transformations associated with affects the steel microstructures and properties.

In this context, this paper studied the effects of different heating cycles and process variables on the phase transformations of a DSS type UNS S32304. This study was performed with a precise induction furnace coupled to a quenching dilatometer.

\section{Materials and Methods}

Samples of duplex stainless steel UNS S32304, with chemical composition presented in Table 1, were kindly supplied by Aperam South America Company for the development of this work. The samples were collected from a hot rolled sheet.

From this initial condition, cylindrical specimens (diameter: $3 \mathrm{~mm}$, length: $10 \mathrm{~mm}$ ) were machined for experiments performed in a quenching dilatometer (LINSEIS R.I.T.A. L78). One of the cylindrical specimens, as received, were microstructural characterized by light optical microscope (OM) (LEICA DM2700M). The other specimens were submitted to different heating cycles as presented in Table 2.

With the samples submitted to the thermal cycles, the following effects were investigated: (1) effect of residence time at maximum temperature $\left(1300^{\circ} \mathrm{C}\right)$ on the austenite dissolution; (2) effect of the austenite decomposition evolution during heating (partial or complete) on the ferrite-austenite transformation during cooling; (3) effect of cooling rate from maximum temperature down to $1050^{\circ} \mathrm{C}$ on the ferrite-austenite transformation; (4) effect of the residence time at maximum temperature on the ferrite grain size.

All the dilatometry specimens, after submission to heating cycles, were cut at the middle length to be analyzed at transversal section by OM. These specimens were prepared according to the procedures suggested by the ASTM E3-01 standard ${ }^{14}$. For contrast analysis the method of Behara II was applied (1g of Potassium Bissulfite; 4.8g of Ammonium Bifluoride; $40 \mathrm{ml}$ of $\mathrm{HCl} ; 80 \mathrm{ml}$ of Distiled Water). The analyzed surface was always the plane which intercept perpendicularly the longitudinal axis of rolling direction.

The samples submitted to the D1, D2, D6-D10 heat treatments were submitted to quantitative metallography procedures (OM) aiming to determine the average ferritic grain size in function of residence time at $1300^{\circ} \mathrm{C}$. The D2 sample was also submitted to a structural analysis by transmission electron microscope (TEM - Tecnai G2-20 -SuperTwin FEI - 200kV) aiming to verify the precipitation of chromium nitrides possibility. This sample was prepared for TEM analysis in a Quanta 3D FEG FEI SEM equipped with focused ion beam (FIB technology).

Considering the steel chemical composition as boundary condition, equilibrium thermodynamic calculations were performed in the software Thermo-Calc windows v5.0 using the base data TCFE6 (TCS Steels/Fe-Alloys Database v6.2) aiming to predict the phase transformations that occurs at the selected temperatures for the heat treatment experiments. Although this software may predict the transformation of many phases from a multicomponent system, in this study, the main focus was the major phases (ferrite and austenite).

\section{Results and Discussions}

\subsection{Microstructural characterization of Initial condition}

The microstructural analysis of initial condition, presented in Figure 1, revealed a common banded aspect of the hot rolled duplex stainless steel. It is possible to observe primary austenite islands (white) in a ferritic matrix (dark areas) ${ }^{1,5}$. The measured volumetric fractions were $33.5 \%$ of austenite and $66.5 \%$ of ferrite. These measured fractions are far from the desired amounts because the studied sheet, when produced, was not submitted to all necessary processes to get the 50 to $50 \%$ ratio of each phase. The sheet was sampled from an intermediate stage of the hot rolling process.

Table 1. Chemical composition of UNS S32304 steel (wt. \%).

\begin{tabular}{cccccccccc}
\hline $\mathrm{C}$ & $\mathrm{Mn}$ & $\mathrm{Si}$ & $\mathrm{P}$ & $\mathrm{S}$ & $\mathrm{Cr}$ & $\mathrm{Ni}$ & $\mathrm{Mo}$ & $\mathrm{N}$ \\
\hline 0.02 & 1.35 & 0.39 & 0.028 & 0.0004 & 22.45 & 3.63 & 0.44 & 0.13 \\
\hline
\end{tabular}


Table 2. Studied heating cycles.

\begin{tabular}{|c|c|c|c|c|c|}
\hline & $\begin{array}{l}\text { Heating until } \\
\text { maximum } \\
\text { temperature }\end{array}$ & $\begin{array}{l}\text { Residence time } \\
\text { at maximum } \\
\text { temperature (s) }\end{array}$ & $\begin{array}{l}\text { Cooling rate until } \\
1050^{\circ} \mathrm{C}\left({ }^{\circ} \mathrm{C} / \mathrm{s}\right)\end{array}$ & $\begin{array}{l}\text { Residence time at } \\
1050^{\circ} \mathrm{C}(\mathrm{min})\end{array}$ & $\begin{array}{l}\text { Cooling rate } \\
\left.\text { untilT } T_{r}{ }^{\circ} \mathrm{C} / \mathrm{s}\right)\end{array}$ \\
\hline D1 & \multirow{10}{*}{$10^{\circ} \mathrm{C} / \mathrm{s}$ until $1300^{\circ} \mathrm{C}$} & 1 & - & - & 200 \\
\hline D2 & & 300 & - & - & 200 \\
\hline D3 & & 1 & 200 & 10 & 200 \\
\hline D4 & & 300 & 200 & 10 & 200 \\
\hline D5 & & 300 & 2 & 10 & 200 \\
\hline D6 & & 5 & - & - & 200 \\
\hline D7 & & 15 & - & - & 200 \\
\hline D8 & & 30 & - & - & 200 \\
\hline D9 & & 60 & - & - & 200 \\
\hline D10 & & 120 & - & - & 200 \\
\hline
\end{tabular}

\section{$* \mathbf{T}_{\mathrm{r}}-$ Room temperature.}

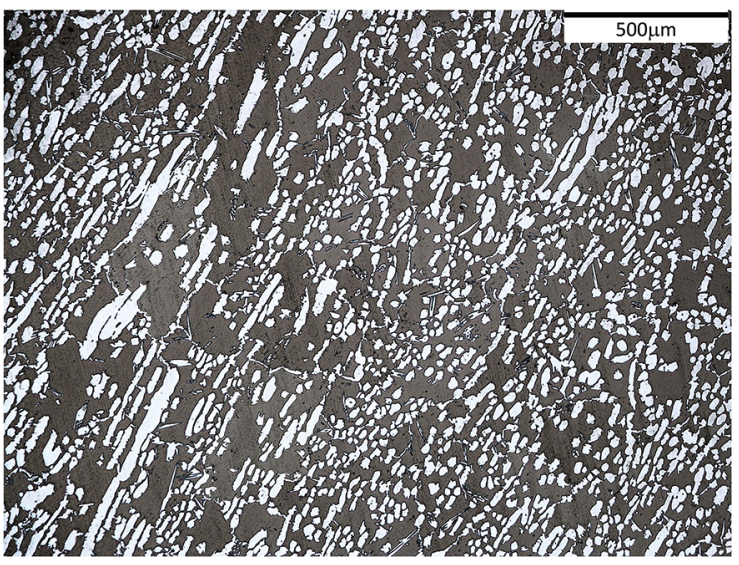

Figure 1. Micrograph of initial condition of UNS S32304 steel. OM - 50x. Behara II. The white phase is austenite and the dark one ferric matrix.

\subsection{Computational simulation}

The Figure 2 presents the results obtained by computational equilibrium simulation in the Software Thermo-Calc. According to the curves, the austenite fraction at maximum temperature $\left(1300^{\circ} \mathrm{C}\right)$ was around $5 \%$ and at $1050^{\circ} \mathrm{C}$ around $50 \%$. According to this simulation, the highest amount of austenite (around 57\%) would be reached in the temperature range between $910^{\circ} \mathrm{C}$ and $915^{\circ} \mathrm{C}$.

\subsection{Effect of partial ferritization}

The D1 heat treatment attempted to simulate the steel heating up to the maximum temperature, but not with enough residence time to decompose all austenite grains into ferrite (partial ferritization). This stage was followed by a fast cooling to prevent the formation of a significant amount of austenite during cooling. The microstructure (Figure 3-a) indicate a decrease in the thickness and amount of the austenite grains. This condition was assumed as partially ferritized. After cooling, the volumetric fraction of austenite

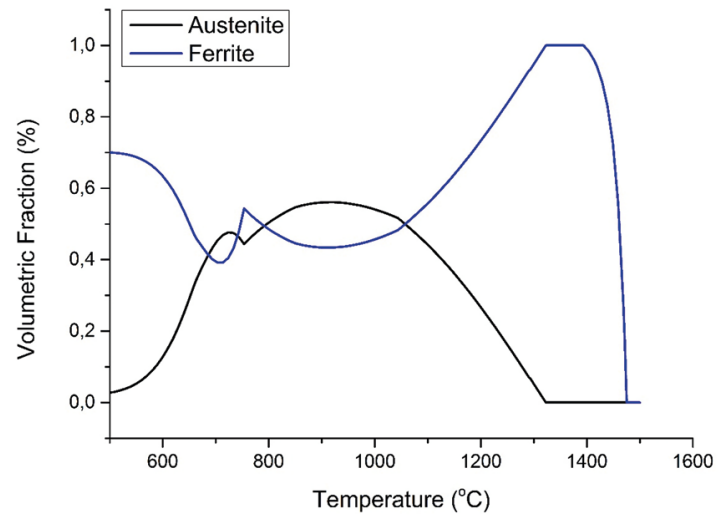

Figure 2. Weight fractions of austenite and ferrite in function of temperature calculated by computational simulation in the Software Thermo-Calc for UNS S32304.

was $18.7 \%$. According to the Thermo-Calc calculations, the equilibrium amount of austenite should be achieved around $5 \%$, which was not verified due to the short time (1s) at maximum temperature $\left(1300^{\circ} \mathrm{C}\right)$.

Figure 3-b shows the duplex microstructure after the heat treatment D3. The microstructure is better balanced, what is very important to reach a good combination of mechanical end corrosion properties. The austenite volumetric fraction was $36.5 \%$, with means a significant increase in relation to the D1 condition. In Figure 3-c, with higher magnification, it is possible to observe that during the sample cooling the new austenite grains form from the preview austenite grains. This occurs due to the incomplete ferritization at $1300^{\circ} \mathrm{C}$ short time isotherm. The boundaries between the remaining primary austenite and ferrite acted as a heterogeneous preferential nucleation site.

According to Garzón e Ramirez ${ }^{9}$, this new formed austenite is named secondary austenite. Its growth is diffusional process which may be influenced by the presence of chromium 


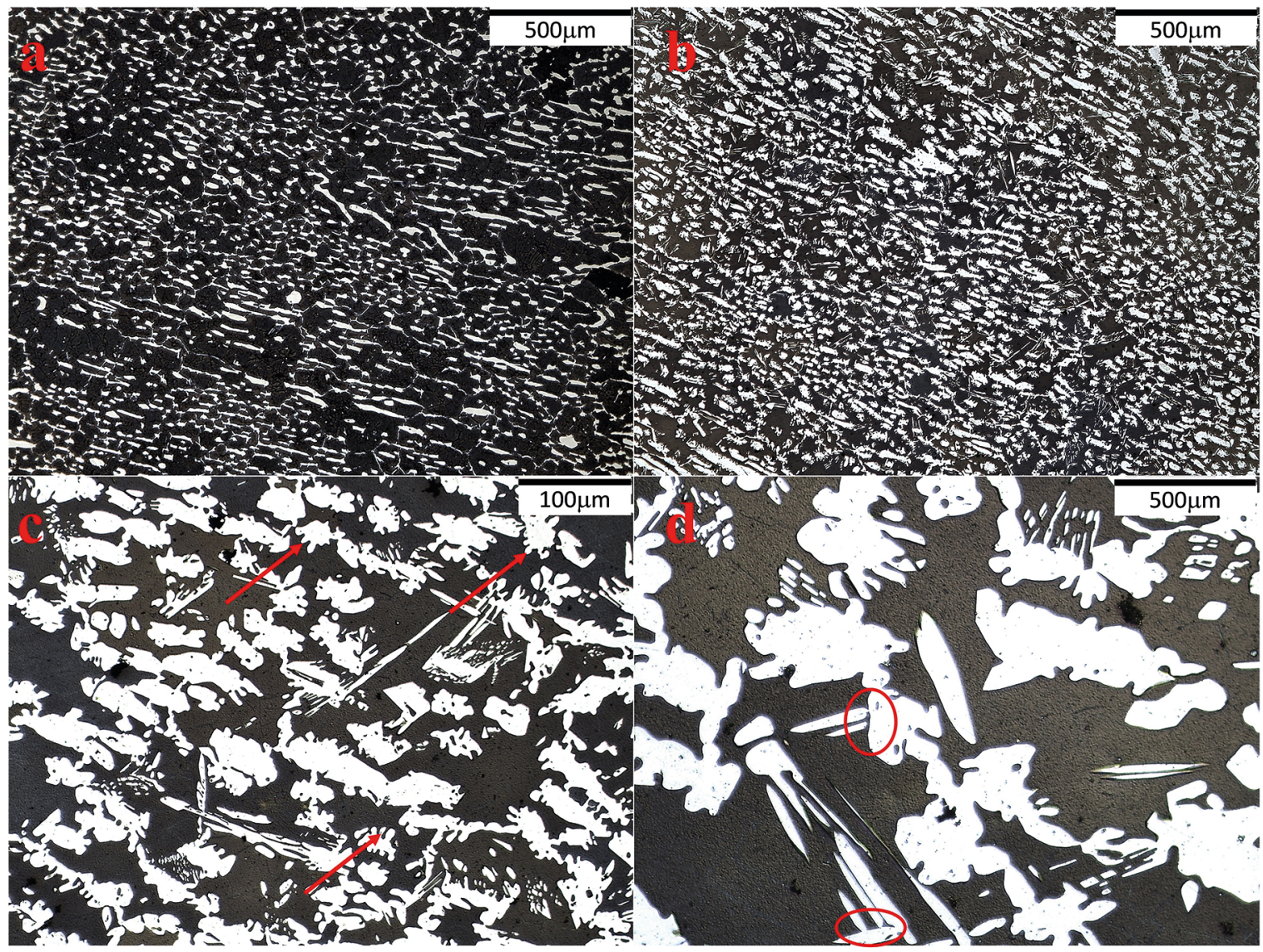

Figure 3. (a) D1 - OM-50x; (b) D3 - OM-50x; (c) D3 - secondary austenite growth (arrows) from primary austenite - OM-200x; (d) D3 - Widmansttäten austenite (circles) originated from a sympathetic nucleation - OM-500x. Behara II.

nitride at austenite/ferrite grain boundaries. According to these authors, as expected for a diffusional mechanism, the higher the temperature the faster the transformation kinetics. However, thicker secondary austenite layers are obtained at intermediate temperatures (around $1050^{\circ} \mathrm{C}$ ) due to a more favorable combination of driving force and atomic mobility9 . The formation of Widmanstätten austenite was observed and might be a result of nucleation at higher temperatures ${ }^{5}$ during the fast cooling from $1300^{\circ} \mathrm{C}$ to $1050^{\circ} \mathrm{C}$. In the Figure 3-d was clearly observed the secondary austenite (highlighted in red) growth from primary austenite grains, as a typical structure from a sympathetic nucleation mechanism ${ }^{15}$, also observed by Chen and Yang ${ }^{3}$ in a 2205 DSS welding heated affected zone.

\subsection{Effect of complete ferritization}

The sample treated in $\mathrm{D} 2$ condition, heated and cooled with the same rates applied in D1, but with difference residence time at $1300^{\circ} \mathrm{C}$, revealed a completely different microstructure (Figure 4). It was evident that the initial microstructure was significantly modified and that the major part of previous austenite transformed to ferrite. This was also observed by other authors that studied welding procedures in 2304 and
$2205 \mathrm{DSS}^{1,3}$. In this paper, this condition was considered a completely ferritized, because there was enough time for almost total austenite decomposition.

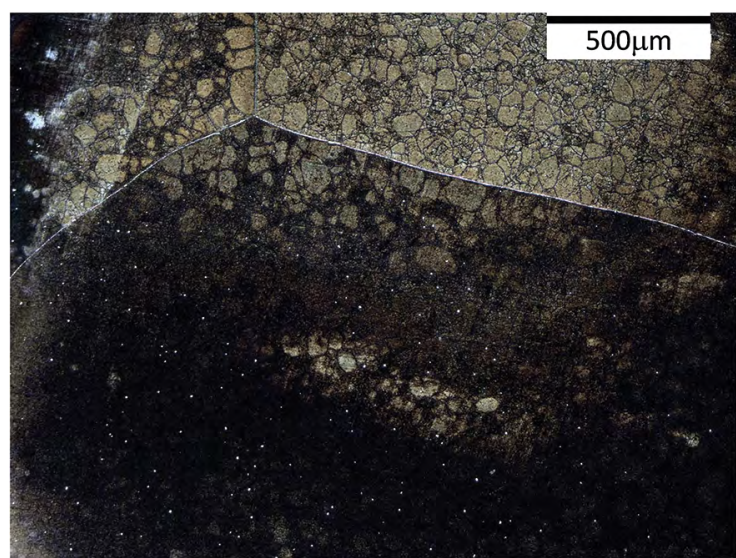

Figure 4. Micrograph of D2 condition. OM-50x. Behara II.

According to Ramirez et al. ${ }^{12}$, the D2 microstructure is a metastable state resulting from the fast cooling from the completely ferritic field. In this condition, the formation 
of chromium nitrides, allotriomorphic and Widmanstätten austenite may be favored. As the cooling rate applied to this condition was $200^{\circ} \mathrm{C} / \mathrm{s}$, there was not enough time for the Widmanstätten formation. However, it is possible to observe a well-defined "string structure" of austenite at ferritic grain boundaries and several dark structures forming a tangle of lines into ferrite grains.

At a higher magnification in an $\mathrm{OM}$, it is possible to observe that this "austenite string" is discontinuous (Figure 5), which is also reported by Muthupandi et al. ${ }^{5}$. The line structures, according to previews studies ${ }^{3,6,16}$, are chromium nitrides precipitated at ferrite subgrain boundaries, where the nitrogen supersaturation on ferrite and the dislocation alignments favor the precipitation phenomena. Besides the allotriomorphic austenite, small austenite grains were observed as disperse points into ferritic matrix. The majority of the small austenite grains were nucleated next to inclusions (Figure 5-b) that work as preferential nucleation points, as the ferrite grain boundaries ${ }^{17}$.

\subsection{Effect of cooling rate from a complete ferritized state}

The Figure 6 shows the microstructure resulted from the D4 treatment. With a fast cooling from a completely ferritized structure, the austenite formation occurred as follow. At higher temperatures allotriomorphic austenite nucleated heterogeneously at ferrite grain boundaries. The Widmanstätten austenite also nucleated at ferrite grain boundaries as well as from the allotriomorphic austenite that has already been formed. They grew preferentially along crystallographic planes of ferritic matrix, in a form of parallel slats. In the ferrite grains (Figure 6-b), different morphologies of austenite were found, including the nucleation of austenite by sympathetic mechanism ${ }^{15,18}$ (Figure 6-c). Intragranular austenite precipitate in relatively low temperatures being favored by the nitrogen supersaturation into ferritic structure ${ }^{3}$.
On the other hand, samples treated in the D5 condition (Figure 7) show significant differences in their microstructures. This happened due to the use of a low cooling rate $\left(2^{\circ} \mathrm{C} / \mathrm{s}\right)$ between $1300^{\circ} \mathrm{C}$ and $1050^{\circ} \mathrm{C}$. In this condition, it was noticed the presence of allotriomorphic, Widmanstätten and intragranular austenite. However, the intragranular austenite are present in small amount and with different distribution when compared to the D4 condition. These intragranular austenite grains occur as fragmented structures (Figure 7-b) that grow as clusters, apparently in preferred orientated directions. The small number of nucleation sites may be explained by the low cooling rate between $1300^{\circ} \mathrm{C}$ and $1050^{\circ} \mathrm{C}$. According to classical theories, low cooling rates promote an increase of critical nucleation radius and a decrease in the density of nuclei that will have thermodynamical conditions to grow ${ }^{17}$. Conversely, as diffusion is enhanced at higher temperatures, the austenite grain growth is improved. This explains the coarser austenite grains more frequently found in samples cooled at lower rates.

According to Garzón and Ramirez ${ }^{9}$, shorter diffusion distances lead to a higher austenite content, because diffusion rates not only depends on distance, on time and temperature, but also on the number of particles (nuclei) per volume unite and of its spatial distribution. It is supposed that, for higher cooling rates and with the decreasing of critical radius, the volumetric density of nuclei increases strongly and the distance between neighbor austenite nuclei decreases. This scenario implies that the supersaturated nitrogen in ferrite grains have to diffuse for shorter distances until it meets one nucleus and contributes to its growth.

The differences of substitutional element concentrations ( $\mathrm{Cr}, \mathrm{Ni}$ and $\mathrm{Mo})$ in ferrite and austenite is much minor than the differences of nitrogen contents ${ }^{12}$, the quickly diffusion of $\mathrm{N}$ will control the austenite growth ${ }^{8}$. So, for slower cooling procedures, where a small amount of nuclei is formed, and the distance for nitrogen diffusion is relatively long, the

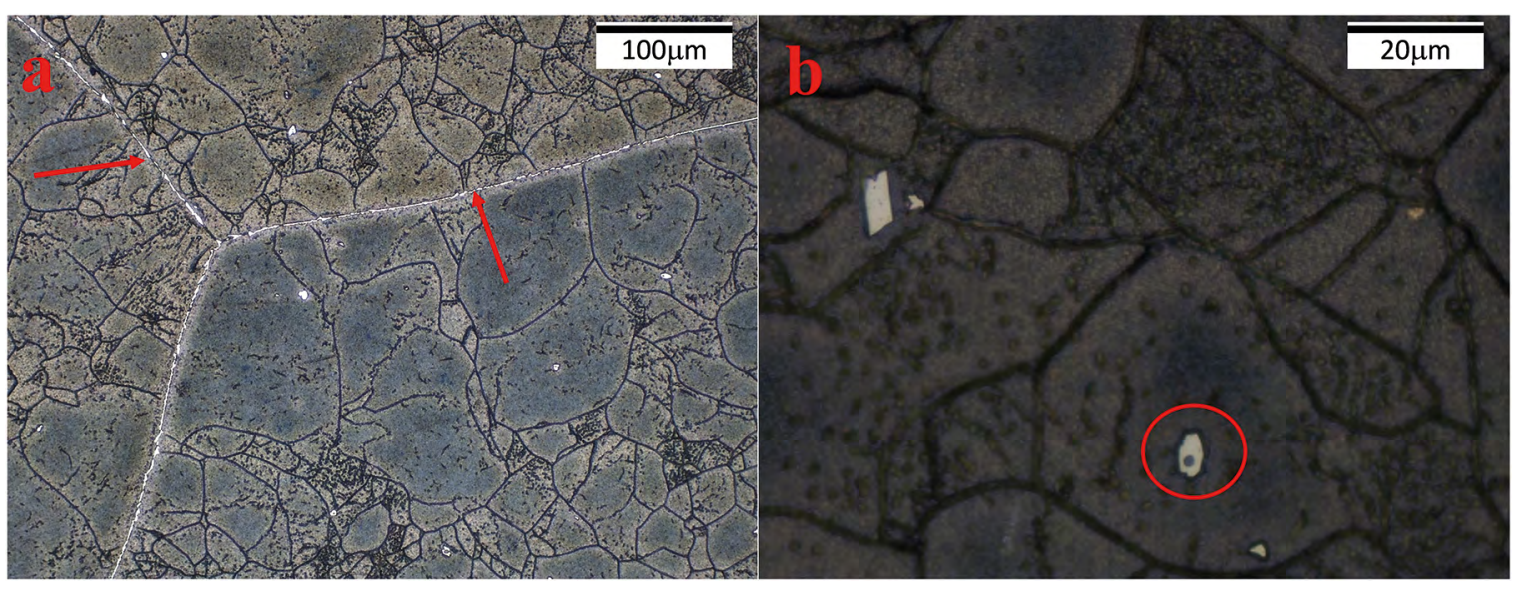

Figure 5. Micrographs of D2 condition (a) austenite polycrystalline string (allotriomorphic austenite, arrows) - OM-200x; (b) Intragranular austenite nucleated from an inclusion - OM-1000x. Behara II. 


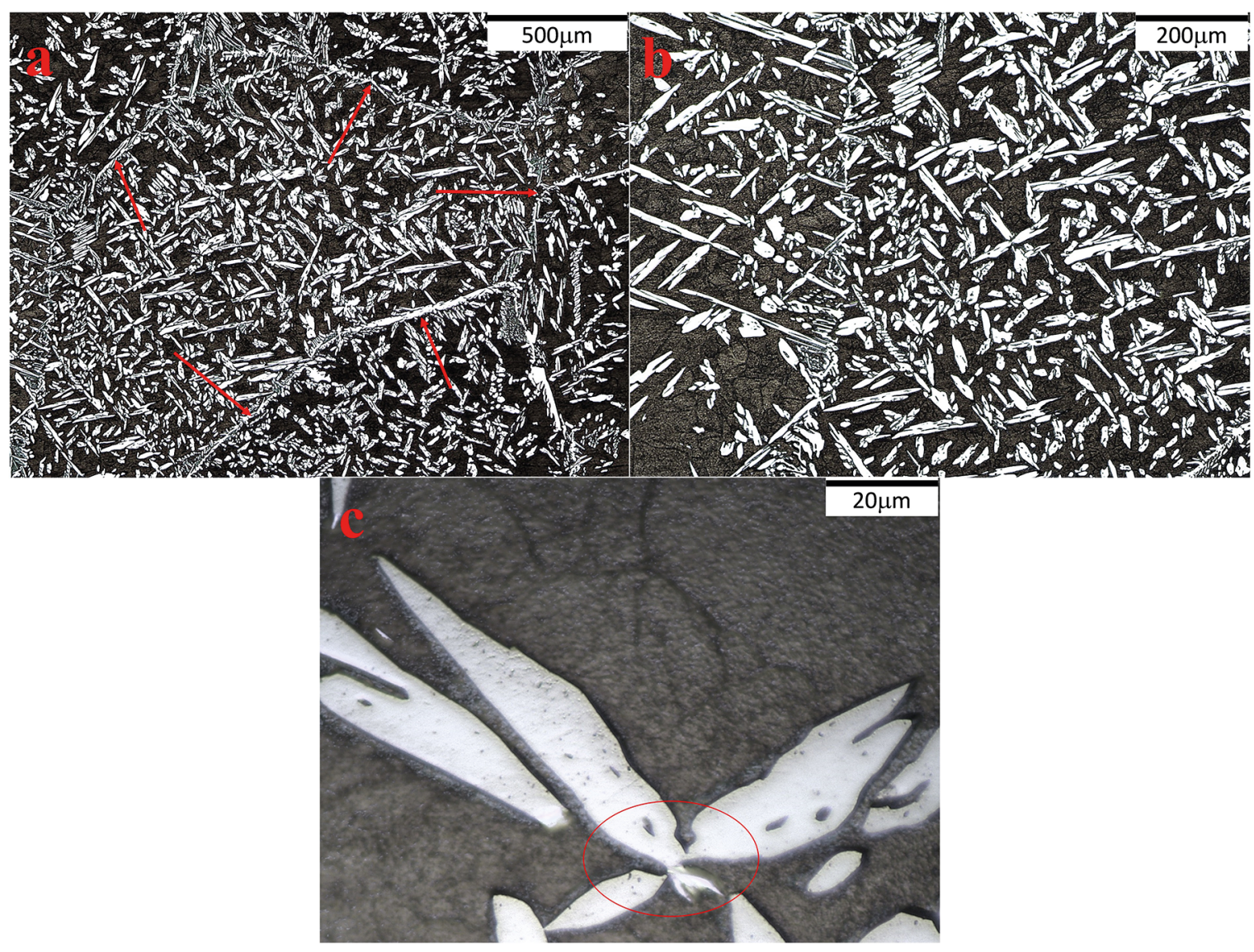

Figure 6. Micrographs of D4 condition (a) allotriomorphic austenite - OM-50x; (b) different coexisting morphologies of austenite OM$100 x ;$ (c) intragranular austenite sympathetically nucleated OM-1000x. Behara II.

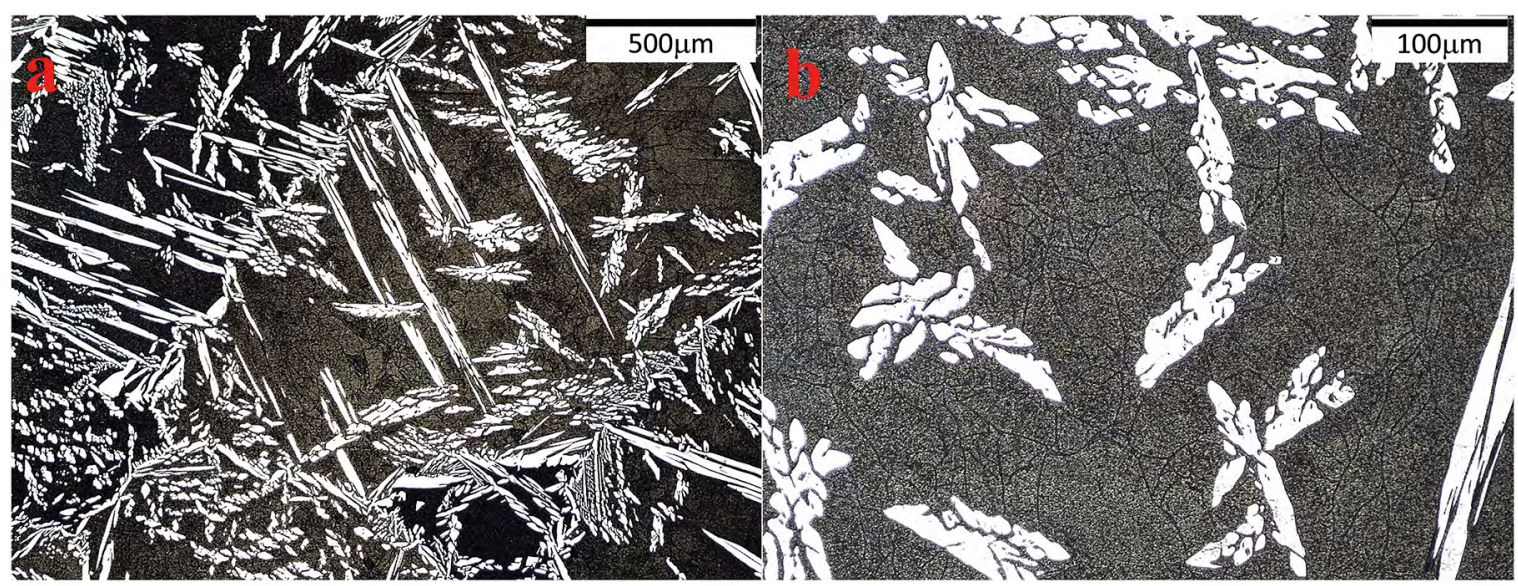

Figure 7. Micrographs of D5 condition (a) OM-50x; (b) clusters of intragranular austenite - OM-200x. Behara II.

austenite growth is slightly affected and then the austenite concentration should be smaller and the chromium nitride precipitation may be favored. In D4 condition, the austenite fraction was $29.6 \%$ and $25.5 \%$ for D5, in accordance to what is expected.

\subsection{Effect of residence time at $1300^{\circ} \mathrm{C}$ on ferrite} grain size
It was observed that ferrite grains, after a complete austenitic dissolution, grow quickly with the residence time at $1300^{\circ} \mathrm{C}$. Figure 8 displays micrographs of heat treated samples at $1300^{\circ} \mathrm{C}$ for different time intervals $(1 \mathrm{~s}, 5 \mathrm{~s}, 15 \mathrm{~s}, 30 \mathrm{~s}, 60 \mathrm{~s}, 120 \mathrm{~s}$ and $300 \mathrm{~s})$ and fast cooled down to room temperature $\left(200^{\circ} \mathrm{C} / \mathrm{s}\right)$. For each sample, the average ferrite grain size was measured. In Figure 9, a graph shows a relationship between the ferrite grain sizes and the residence time at $1300^{\circ} \mathrm{C}$. The 


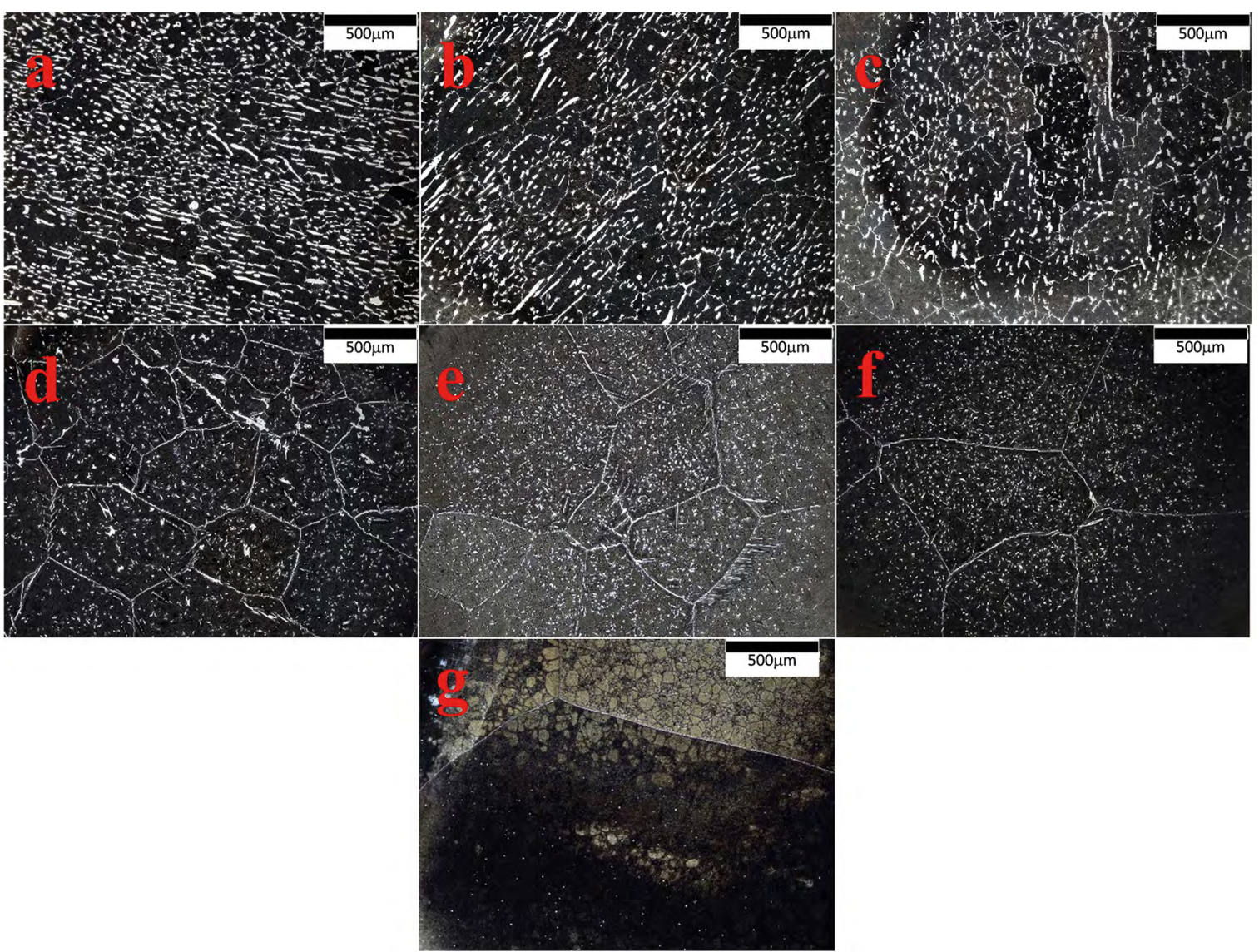

Figure 8. Micrographs of samples held at $1300^{\circ} \mathrm{C}$ for different time intervals (highlighting ferrite grain sizes). (a) $1 \mathrm{~s}$; (b) $5 \mathrm{~s}$; (c) $15 \mathrm{~s}$; (d) 30s; (f) 60s; (g) 120s; (h) 300s. OM-50x. Behara II.

ferrite grain size is directly proportional to the square root of time. Burk and Turnbul1 ${ }^{19}$, studying the grain growth mechanism for several steels found the same correlation, as presented in equation 1. A non-linear fit was applied to the experimental data and a proportionality constant $(\mathrm{K})$ of $(65$ $\pm 2) \mu \mathrm{m} . \mathrm{s}$ was determined using the Equation 1.

$$
F G S=K * \sqrt{t} \quad \text { Equation (1) }
$$

\subsection{Chromium nitride}

During the austenite decomposition, the ferrite starts to be supersatured in alloy elements. The concentration of alloy elements such as $\mathrm{Mn}, \mathrm{Ni}, \mathrm{C}$ and $\mathrm{N}$ increases and eventually gets over saturated. Among them, the effect of nitrogen must be highlighted, because the solubility of this element in ferrite decreases strongly during the cooling ${ }^{1}$, leading to the chromium nitride precipitation inside ferrite grains. An EBSD-SEM analysis of the samples submitted to D2 condition (Figure 10) showed the presence of $\mathrm{CrN}$ (mainly at ferrite grain boundaries, green color in Figure 10) and $\mathrm{Cr}_{2} \mathrm{~N}$. The sample from the heat treatment $\mathrm{D} 2$ was chosen because it favors the supersaturation of nitrogen in

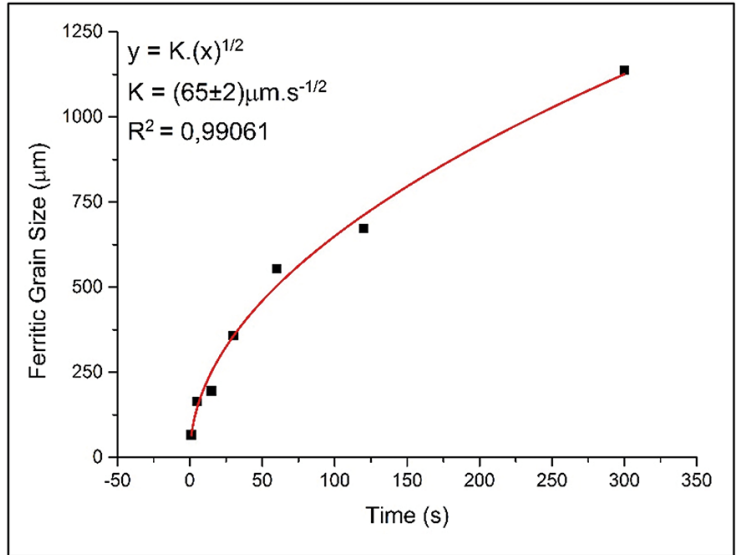

Figure 9. Ferrite grain size versus residence time at $1300^{\circ} \mathrm{C}$ for UNS S32304 stainless steel.

ferrite (total ferritization) and, consequently, the precipitation during the fast cooling. The $\mathrm{CrN}$ has a cubic $\mathrm{NaCl}$ structure (space group Fm-3m) ${ }^{20}$. The $\mathrm{Cr}_{2} \mathrm{~N}$ has a trigonal structure forming a hexagonal subcell (spatial group P-31m) ${ }^{12}$. 


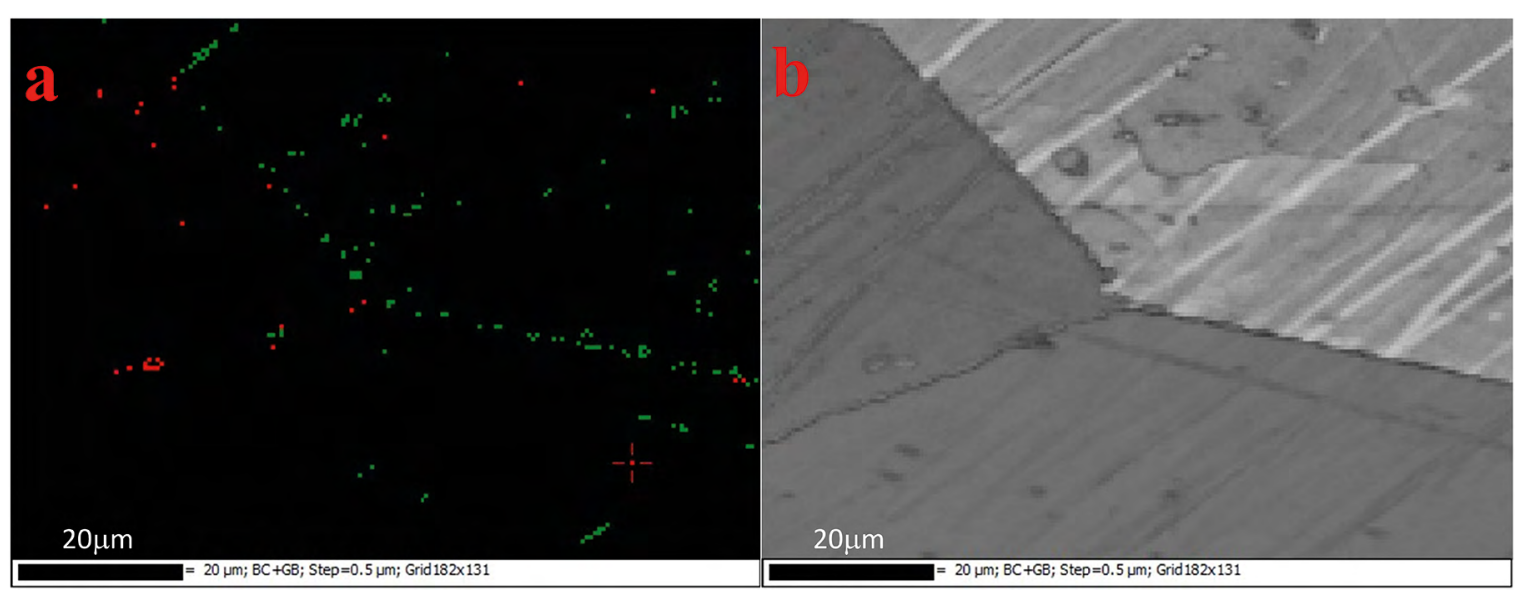

Figure 10. EBSD-SEM results for $\mathrm{D} 2$ condition (a) $\mathrm{CrN}$ (green points mainly at grain boundaries) and $\mathrm{Cr}_{2} \mathrm{~N}$ (red points); (b) Band Contrast.

The electrolytic etching with oxalic acid (Figure 11) highlighted the presence of chromium nitrides at subgrain boundaries, as predicted by Ramirez et. al. ${ }^{12}$.

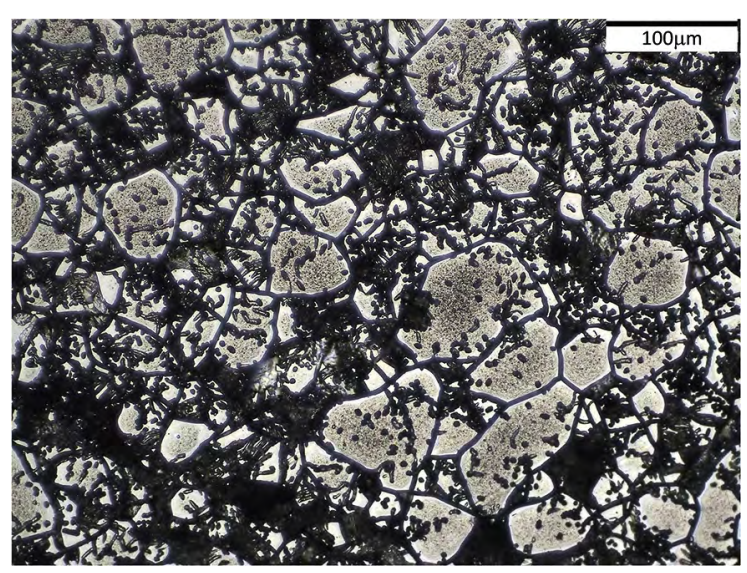

Figure 11. Micrographs of D2 condition revealing the chromium nitride presence. Electrolytic etching with oxalic acid. OM-200x.

A TEM analysis confirmed the presence of precipitates as tiny needles (Figure 12-a and 12-b), typical of chromium nitrides. The sample submitted to TEM analysis was prepared in a FIB and its dimensions were very small. Due to that, the cellular structures observed in Figure 11 could not be observed. Chen and Yang ${ }^{3}$ observed that diffraction profile of some ferrite planes and $\mathrm{Cr}_{2} \mathrm{~N}$ may be very close to each other as seen in Figures 12-c and 12-e. The Figures 12-d and 12-f correspond to the elastic scattering collected from the diffraction profiles. As seen in these figures there is a good match between the crystallographic orientation of ferritic matrix and the precipitated needles.

\section{Conclusions}

The austenite fraction predicted by Thermo-Calc computational simulation is in a good match with the data obtained at $1300^{\circ} \mathrm{C}$ for a constant temperature for 5 minutes. The time was enough for system to reach close to the thermodynamic equilibrium condition. The prediction for austenite fraction at $1050^{\circ} \mathrm{C}$ was higher than those obtained experimentally because several parameters affected the kinetic transformation during steel cooling: size and geometry of ferritic grains, chromium nitride precipitation and diffusion of austenite stabilizer elements (mainly nitrogen).

The time intervals from $1 \mathrm{~s}$ to $120 \mathrm{~s}$ at $1300^{\circ} \mathrm{C}$ was not enough for a complete dissolution of the austenite, so a partial ferritized structure is obtained. The cooling from a partial ferritized structure led to a formation of a new austenite from the originally no dissolved austenite grains, which kept the banded microstructure. In this case, the austenite total fraction was the highest measured when compared to the other heat treated samples. The sympathetic nucleation of Widmanstätten austenite was observed.

The fast cooling $\left(200^{\circ} \mathrm{C} / \mathrm{s}\right)$ down to the room temperature of a completely ferritized and supersaturated structure $\left(1300^{\circ} \mathrm{C}\right.$ for $5 \mathrm{~min}$ ) produced an abundant precipitation of chromium nitrides at ferrite subgrain boundaries and fine strings of allotriomorphic austenite. A small amount of intragranular austenite grains was found mainly at intersections between inclusions and the ferritic matrix.

The cooling down to $1050^{\circ} \mathrm{C}$ (with a $10 \mathrm{~min}$. of residence time at this temperature), starting with a completely ferritized and supersaturated structure, led to the formation of allotriomorphic, Widmanstätten and intragranular austenite. If the cooling rate until $1050^{\circ} \mathrm{C}$ is high $\left(200^{\circ} \mathrm{C} / \mathrm{s}\right)$, the austenitic structures are more fine and well distributed in all matrix. 


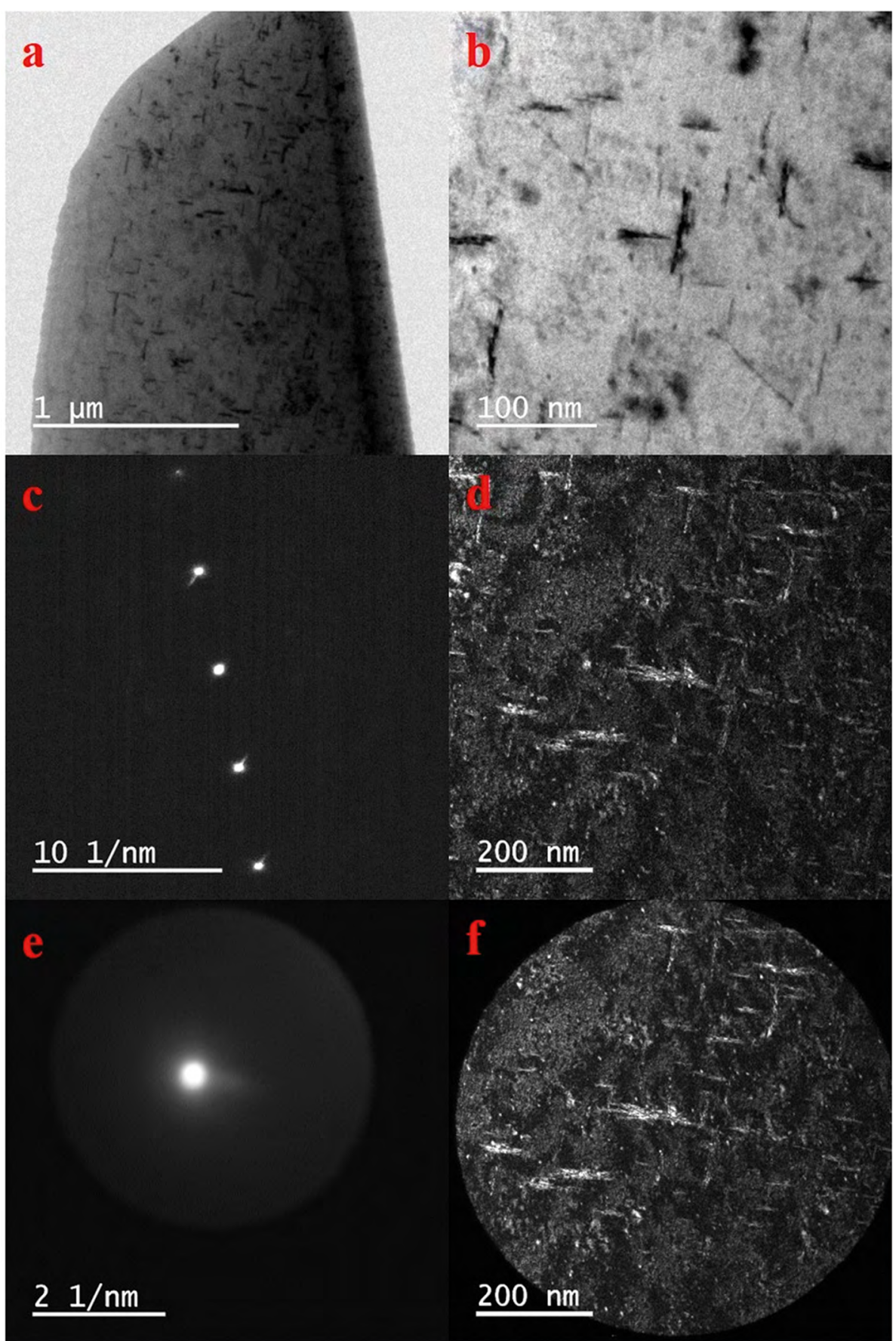

Figure 12. (a) TEM micrograph of D2 sample; (b) Detail of TEM micrograph showing the chromium nitrides in detail, highlighting the needles morphology; (c) Diffraction profile of ferritic matrix coincident with $\mathrm{Cr}_{2} \mathrm{~N}$; (d) elastic scattering image correspondent to the Fig. 12-c; (e) Detail of diffraction profile of ferritic matrix coincident with $\mathrm{Cr}_{2} \mathrm{~N}$; (f) elastic scattering image correspondent to the Fig. 12-e.

If the cooling rate is slow $\left(2^{\circ} \mathrm{C} / \mathrm{s}\right)$, the resulting austenitic structures are coarser and occur as clusters. The fast cooling from a temperature where a completely ferritized structure is formed to $1050^{\circ} \mathrm{C}$ promotes higher volumetric fractions of austenite when compared to the slow cooling. Therefore, the mechanism which control the austenite reformation is diffusional and strongly influenced by nitrogen diffusion.

The ferrite grain size of UNS S32304 alloy is directly proportional to the square root of residence time at $1300^{\circ} \mathrm{C}$. It can be said that the size of ferritic grain grows as the primary 
austenite is dissolved and that, consequently, a completely ferritic structure, in this case, is formed by equiaxial coarse grains. If the growth of the ferritic grains during the heating step in a thermal processing is not controlled, the fraction, types and morphology of the reformed austenite during cooling may be quite different from that expected in a balanced microstructure. Thus, ferritization during heating can drastically alter the reforming of austenite during any type of cooling.

The observed precipitates in EBSD and TEM analysis were identified as $\mathrm{CrN}$ and $\mathrm{Cr}_{2} \mathrm{~N}$. These structures with needle shape precipitate from a supersaturated nitrogen ferrite, impairing the austenite nucleation and growth.

\section{Acknowledgments}

The authors would like to acknowledge the Coordenação de Aperfeiçoamento de Pessoal de Nível Superior (CAPES) for the financial support.

\section{References}

1. Tan H, Wang Z, Jiang Y, Han D, Hong J, Chen L, et al. Annealing temperature effect on the pitting corrosion resistance of plasma arc welded joints of duplex stainless steel UNS S32304 in 1.0 $\mathrm{M} \mathrm{NaCl}$. Corrosion Science. 2011;53(6):2191-2200.

2. Muthupandi V, Srinivasan PB, Seshadri SK, Sundaresan S. Effect of weld metal chemistry and heat input on the structure and properties of duplex stainless steel welds. Materials Science and Engineering: A. 2003;358(1-2):9-16.

3. Chen TH, Yang JR. Microstructural characterization of simulated heat affected zone in a nitrogen-containing 2205 duplex stainless steel. Materials Science and Engineering: $A$. 2002;338(1-2):166-181.

4. Chen L, Tan H, Wang Z, Li J, Jiang Y. Influence of cooling rate on microstructure evolution and pitting corrosion resistance in the simulated heat-affected zone of 2304 duplex stainless steels. Corrosion Science. 2012;58:168-174.

5. Muthupandi V, Srinivasan PB, Shankar V, Seshadri SK, Sundaresan S. Effect of nickel and nitrogen addition on the microstructure and mechanical properties of power beam processed duplex stainless steel (UNS 31803) weld metals. Materials Letters. 2005;59(18):2305-2309.

6. Guo Y, Sun T, Hu J, Jiang Y, Jiang L, Li J. Microstructure evolution and pitting corrosion resistance of the Gleeble-simulated heataffected zone of a newly developed lean duplex stainless steel 2002. Journal of Alloys and Compounds. 2016;658:1031-1040.
7. Dobranszky J, Szabo PJ, Berecz T, Hortko V, Portko M. Energydispersive spectroscopy and electron backscatter diffraction analysis of isothermally aged SAF 2507 type superduplex stainless steel. Spectrochimica Acta Part B Atomic Spectroscopy. 2004;59:1781-1788.

8. Hertzman S, Brolund B, Ferreira PJ. An experimental and theoretical study of heat-affected zone austenite reformation in three duplex stainless steels. Metallurgical and Materials Transactions A. 1997;28(2):277-285.

9. Garzón CM, Ramírez AJ. Growth kinetics of secondary austenite in the welding microstructure of a UNS S32304 duplex stainless steel. Acta Materialia. 2006;54(12):3321-3331.

10. Liou HY, Hsieh RI, Tsai WT. Microstructure and pitting corrosion in simulated heat-affected zones of duplex stainless steels. Materials Chemistry and Physics. 2002;74(1):33-42.

11. Liou HY, Hsieh RI, Tsai WT. Microstructure and stress corrosion cracking in simulated heat-affected zones of duplex stainless steels. Corrosion Science. 2002;44(12):2841-2856.

12. Ramirez AJ, Lippold JC, Brandi SD. The relationship between chromium nitride and secondary austenite precipitation in duplex stainless steels. Metallurgical and Materials Transactions A. 2003;34(8):1575-1597.

13. Sieurin H, Sandström R. Austenite reformation in the heataffected zone of duplex stainless steel 2205. Materials Science and Engineering: A. 2006;418(1-2):250-256.

14. ASTM International. ASTM E3-01 - Standard Practice for Preparation of Metallographic Specimens. West Conshohocken: ASTM International; 2001.

15. Aaronson HI, Spanos G, Masamura RA, Vardiman RG, Moon DW, Menon ESK, et al. Sympathetic nucleation: an overview. Materials Science and Engineering: B. 1995;32(3):107-123.

16. Perren RA, Suter T, Solenthaler C, Gullo G, Uggowitzer PJ, Böhni $\mathrm{H}$, et al. Corrosion resistance of super duplex stainless steels in chloride ion containing environments: investigations by means of a new microelectrochemical method: II. Infuence of precipitates. Corrosion Science. 2001;43(4):727-745.

17. Novikov I. Teoria dos Tratamentos Térmicos dos Metais. Rio de Janeiro: UFRJ; 1994.

18. Chen CY, Yen HW, Yang JR. Sympathetic nucleation of austenite in a Fe-22Cr-5Ni duplex stainless steel. Scripta Materialia. 2007;56(8):673-676.

19. Burke JE, Turnbull D. Recrystallization and grain growth. Progress in Metal Physics. 1952;3:220-244, IN11-IN12, 245266, IN13-IN14, 267-274, IN15, 275-292.

20. De Lacerda JC, Cândido LC, Godefroid LB. Corrosion behavior of UNS S31803 steel with changes in the volume fraction of ferrite and the presence of chromium nitride. Materials Science and Engineering: A. 2015;648:428-435. 